\title{
LEADERSHIP AND CONFLICT MANAGEMENT IN PRODUCTION ORGANISATIONS
}

\author{
Jerko GLAVAŠ, Veljko KONDIĆ, Iva BALIĆ
}

\begin{abstract}
Conflicts between different interests are inevitable in every business organization. Therefore, it is not surprising that the number and intensity of conflicts is sometimes very high. Conflict resolution is a skill without which managers can hardly succeed in their business. The subject of research in this paper is conflict management from a technical and economic point of view. The paper defines and analyzes the notion of leadership, that is, elements and dimensions of leadership, the notion of leader, and theoretical approaches to leadership. In addition to the above, the concept of conflict, more specifically its type, levels of conflict, consequences and causes, and techniques of conflict resolution have been defined and analyzed. An online survey (based on the Linkedln Business Social Network) was conducted to determine how individuals in a production organization respond and resolve conflicts as well as the results of the same. Based on theoretical scientific approach, the conducted research and the analysis of the results, conclusions and recommendations are given, as well as key questions for future research.
\end{abstract}

Keywords: conflict; leadership; management; production organization

\section{INTRODUCTORY CONSIDERATIONS}

Leadership is considered to be one of the most important factors for a company's success. The notion of leadership is very complex, which is why there are many variations in defining it. Within this thesis, leadership will be seen as the ability to influence the group in terms of managing conflicts to achieve organizational goals.

In conflict situations, the role of the leader is to direct and motivate employees, all for the purpose of completing their work tasks, in order to contribute to the achievement of the organization's goals through their actions and reflections.

Table 1 Overview of leadership definitions [1]

"Leadership is the ability to influence, inspire and direct individuals or groups toward achieving goals." (Bass, M. B., 1985: 9)

"Leadership is the art or process of influencing people, so that they readily and enthusiastically strive for group goals." (Koontz, H., Weihrich, H., 1994: 437)

"Leadership is the ability to influence, inspire, and direct the actions of individuals or groups toward the desired goals." (Hellriegel, D., Slocum, J. W., 1989: 465)

"Leadership is the process of influencing the activities of individuals or groups towards the achievement of goals." (Gatewood, D. R., Taylor, R. R., Farell, O. C. 1995: 7)

"Leadership is the ability to influence people toward their goals. Leadership is mutual (reciprocal), it takes place among people. Leadership is a "human" activity, different from administrative paperwork or problem solving activities. Leadership is dynamic and involves the use of power to influence people to move toward goals." (Daft, L. R. 1997: 590)

"Leadership is a process and a caracteristic. As a process - focusing on what the leader is currently doing - leadership is the use of non-coercive influence to shape group or organizational goals, motivate behavior toward those goals, and help define a group or organizational culture. As an attribute, leadership is a set of characteristics of individuals who are perceived as leaders." (Griffin, W. R., 2002: 520)

While we define management as the process of directing others toward the accomplishment of a particular task, the emphasis is more on the ability to influence others who perform certain tasks. Leadership is actually the only real function of management because it cannot be delegated to others, while for all other functions special departments can be organized, such as for planning, organizing, human resources management, etc. Leadership is considered one of the most important factors for the success of a company. The notion of leadership is very complex, which is why there are many variations in defining it. Different views on the conceptual definition of leadership result from the fact that different authors define leadership most often according to their personal views and the viewpoint of the phenomenon that interests them most, resulting in numerous definitions of leadership. The following table shows some of the definitions of leadership by different authors.

Leadership represents the ability to influence a group in terms of achieving goals, and the source of that influence can be formal, such as the influence that ensures a managerial position in an organization. Managerial positions most often come with some degree of formally established authority, which is why individuals may consider that a leadership role derives from the position a manager has in an organization. Not every leader is a manager, nor is every manager a leader. Even though an organization provides certain rights to its managers, this does not mean that managers will be able to lead effectively. Equally important or more important than formal influence is the non-sanctioned leadership, that is, the capacity to influence outside of the formal structure of the organization. In simplified terms, leaders can emerge from the ranks of the group just as they can be formally appointed.

\subsection{Leadership as Management Tool}

Leadership is generally understood as the most demanding managerial function. One definition is that leadership is actually the art of influencing people so that they willingly and enthusiastically strive to achieve the goals of the organization. Srića [2] defines leadership as "the ability to influence the behavior of associates and their value system to achieve the goals of the organization with enthusiasm". Karlic and Hadelan [3] state that "current knowledge of the leadership process suggests that it is a dynamic process that requires creativity and organization in order to coordinate ongoing business activities while starting new and extinguishing old ones." 
Although leadership definitions differ, most contain essential components that are common to all.

Leadership dimensions comprise specific leadership features that make it possible to find, explain, and evaluate differences that exist in leadership content, and are the result of researchers' understanding of the features that make leadership effective. Leadership is a process in which an individual influences a group in order to achieve a common goal. Following the above definition, we see that being a leader means an important interaction with their followers or team members. Transactional leadership is the one in which a group of people is focused on a common goal, although it is not expected of individuals to be proactive, but to perform the tasks that are intended for them. [8]

\subsection{Leadership Dimensions and Impact on Conflict}

Leadership has been one of the most important variables in interpreting organizational results and the employees' work behaviour. In turn, the classic theories focused either on the characteristics of leaders, on their behaviour, on the environmental factors, or on their interactions with the followers in order to construct interpretations for conduct, efficiency and effectiveness of workers and organizations (Horner, 1997; Van Seters and Field, 1990). Key criteria for this interpretation were the two classic approaches to leadership outlined by the scholars of Ohio State University and the University of Michigan, namely the "consideration, or employee orientation, or peopleoriented leadership" and the "initiation of structure, or production orientation, or taskoriented leadership" (Armandi et al., 2003; Avolio, 2007; Silva, 2015). Bass (1985, as cited in Bass, 1990), based on the emerging concepts of charismatic leadership, initiated by House (1977, as cited in House, 1996) and transformational leadership, devised by Burns (1978, as cited in Yammarino and Bass, 1990) established a new leadership model known as Multifactor Leadership Theory which included the Transformational, Transactional and Laissez-faire Leadership types (Bass, 1990; Bass and Avolio, 1990). Subsequently, Bass and Avolio (1992; 1995) initiated a full research questionnaire named the Multifactor Leadership Questionnaire/MLQ in order to measure and evaluate these new types of leadership and their particular characteristics and effects. [10]

For a long time, it has been a common belief that organizing and operating a business is a rational process in which emotions have no place. Today it is considered that the expression of positive emotions has a very positive effect, which is most pronounced when connected emotionally and rationally, while the neglect of emotions can lead to tragic results. Emotional intelligence is considered the skill of recognizing one's own feelings as well as that of other people, motivating oneself, and managing their emotions and relationships well. Many authors consider emotional intelligence to be more important for high-performance jobs and for the highest levels of leadership than for cognitive and technical skills. Effective leadership requires excellently developed emotional intelligence, and good leaders use their own emotional intelligence rather than positional power.
Emotional intelligence, along with cognitive skills, is crucial in identifying and promoting shareholder value, which supports the execution of vision, mission and strategies.

At the beginning of the twentieth century, when the research of leadership and characteristics of a successful leader began, personal traits were the starting point, as indicated by Yammarino et al.. Cowley very early indicated that it was believed that leaders were born, not made and that it was a matter of genetic predisposition whether someone would become a successful leader or not. Further research raised the question of leadership's behaviour and, therefore, in the second half of the twentieth century, many theories of leadership styles that describe leadership ranging from authoritarian (i.e. task-oriented leadership style) to democratic (i.e. peopleoriented leadership style) appeared.

In addition, the attitude that leaders are born, not made has changed into the attitude that leadership is a skill that can be learned. The continuation of scientific research on leadership showed that the personality of the leader and his behaviour are not the only factors, which have an impact on the successful leadership style, but that it is also necessary to take situational factors into account. In other words, the leader should first define factors that are crucial in a particular situation in order to apply the appropriate leadership style in accordance with requirements of the situation. [14]

Garaca [4] states that the job of leadership has first and foremost an interpersonal dimension, but also a technical one, which means quality, efficiency and productivity.

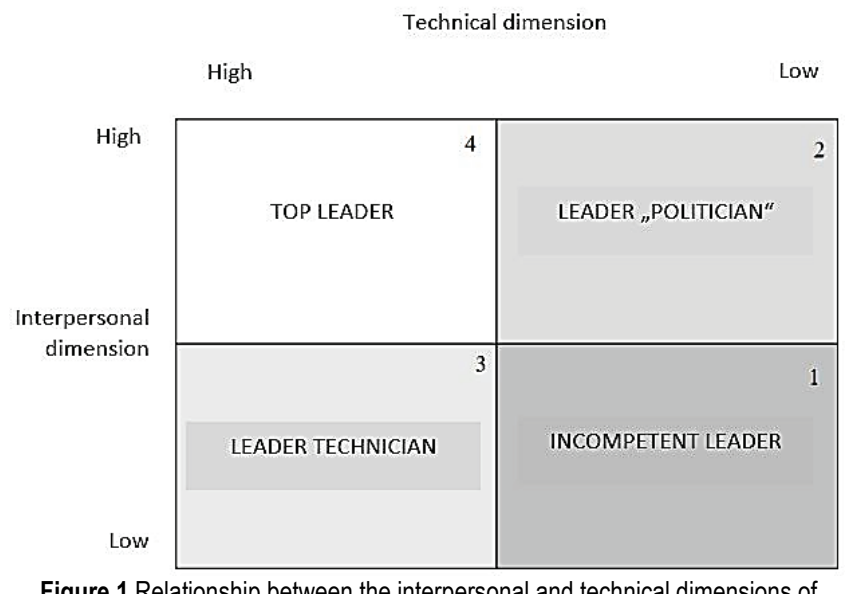

Figure 1 Relationship between the interpersonal and technical dimensions of leadership [4]

The incompetent leader is weak in both technical and interpersonal skills. A politician is a type of leader who lacks technical knowledge, but is good in the interpersonal and social, which is of greater importance when it comes to leadership. The technician is strong in technical knowledge but weak in interpersonal relationships. A top leader is a leader who has all the necessary leadership qualities.

\subsection{Conflict as a Business Chance}

The issue of conflicts and conflict behavior of the person becomes more and more relevant in different aspects. First of 
all, it is connected with the continuing and even increasing conflicts between countries, peoples, ethnic groups, which are clearly observed recently in some regions of the world. In addition, it is associated with a competitive relationship between organizations. Conflicts are an inevitable way of resolving contradictions in any organization. For today's organizations is characterized by a wide variety of conflicts caused by different reasons, they become involved as separate individuals, and groups, driven by different interests and needs that conflict forms the vast space. And naturally this actualizes the issue of studying conflicts and their causes, resolution and management. [11]

A modern trend of study of conflicts is the search for interdisciplinary approaches to understanding the causes and manifestations of conflict behavior in an organization, such as interdisciplinary business psychology approach. This approach combine the psychological and managerial basics. Psychological aspects, are concerned with the nature of conflict behavior and factors of conflict resolution. Conflict is considered as a lack of agreement between two or more parties, individuals or groups, the clash of their opposing interests (Antsupov, Shipilov, 2000 Grishina, 2008). Managerial approach is focused on conflict resolution and conflict management in an organization: on politics as cases give rise to conflict of employee and group of employees (George, Jones, 2007), capabilities of successful organization in the conflict management mechanism for conflict resolution and improving performance (Hart, 2000) etc. That is why the business psychology pay attention on psychological mechanisms and factors of conflict and its importance for the conflict management. [11]

For people in the organization, but also for those who are just watching, either directly or indirectly, conflicts in the organization can be very frustrating. For this other group, it is not very comfortable to work in an environment where two people are constantly fighting and are hostile to one another. Conflicts, by themselves, do not necessarily have to be bad, but have both positive and negative sides. A certain level of conflict within an organization can have positive consequences not only for individuals and groups, but for the organization as a whole. They give people the opportunity to identify problems and opportunities that go unnoticed, and as a result increase creativity and productivity. Successful managers know how to foster constructive conflict in situations where the existing status quo impedes change and development.

"The Positive Consequences of Conflict:

- Improves the quality of decisions made

- Encourages creativity and innovation

- Increases interest and curiosity in the group

- Becomes a mean of reducing tension

- Allows better adaptation to changes.

$$
\begin{array}{ll} 
& \text { Negative Consequences of Conflict: } \\
\text { - } & \text { Dissatisfaction } \\
\text { - } & \text { Weakening of interconnections } \\
\text { - } & \text { Decrease in work performance } \\
\text { - } & \text { Poor communication among members }
\end{array}
$$

- Fighting among members becomes more important than doing the job." [5]

When faced with conflict situations, people use one of the following strategies to resolve them:

- "Avoidance is the physical or mental withdrawal from conflict. In this situation, both sides pretend that the conflict does not exist and hope that it will somehow disappear on its own." [5]

- Indulgence is characterized by adjusting to the interests of the other person, that is, one party to the conflict cares more about the other person than about himself, and most often to his detriment. With this technique, people try to reduce the differences between them and emphasize the similarities and what they have in common, which can work for a certain time, but this causes the conflict to be resolved and after a while the conflict may break even more and result in even more frustration and resentment.An individual's behavior can range from immediate behavior to a willingness to relent after a brief reflection on the situation. As stated by Rijavec and Miljković [5], "a person's behavior can act positively, and after a while it may begin to show a so-called passive-aggressive behavior, ie stubbornness, forgetting and the like."

- Imposing is the use of power to accomplish your goals. It is based on aggression and domination, and one person in a conflict thinks only of their desires and completely neglects the other. The imposition can also take the form of command, in such a way that a person with formal power orders another person to do what he has to do. "But in a positive case, this style may include a willingness to understand and respect another person's position. A person wants to explain, prove, and impose his or her attitude, but it also allows the other party to do it. "[5] In a competitive environment, people have to fight for respect and influence, which is why they often pretend to be more confident in themselves than they really are. The consequence is that they do not actually dare to ask for the information they need and learn more slowly and do less well.

- Compromise is the search for the most optimal solution or the willingness to give up something in exchange for something else. Compromise means to take care of himself and others without the outcome of gain or loss. Although the conflict may seem resolved, it may reemerge after a while.

According to Rijavec and Miljković [5], "cooperation is an open and direct confrontation with the conflict and the search for a mutually satisfactory solution." One conflict person is trying to get both people to the maximum and results in a win-win position. Collaboration requires the most precious things in the organization, which are time and energy. Insignificant problems do not require perfect solutions but can be solved in any way since the consequences are irrelevant. Likewise, not every personal conflict is necessarily resolved. Excessive use of a cooperative strategy may indicate that one person in conflict 
does not want to take responsibility or that he or she wants to delay something that should actually be done.

\section{CONFLICT MANAGEMENT IN ORGANIZATIONS: EMPIRICAL RESEARCH}

The aim of the research was to investigate how people respond to and manage workplace conflicts. For the purpose of the research, the authors conducted a survey containing 15 questions with offered answers, of which only one had to be selected. The answers to the questions from line 3 to line 12 have offered answers from 1 to 5 . Number 1 represents a situation that never happens, number 2 rarely, number 3 sometimes, number 4 often and number 5 always.

The basic hypothesis: H1: Conflicts in the organization are under the direct supervision of employees and managers. The survey was approached by 82 respondents of different age groups, of whom 56 were female and 26 were male. The survey lasted from August 26 to September 9, 2019 in Osijek. The research is done electronically (via the LinkedIn Business Social Network). The survey included a request to complete the survey and a brief explanation of the survey and its purpose. After the data were collected, these were analyzed by the statistical methods shown below.

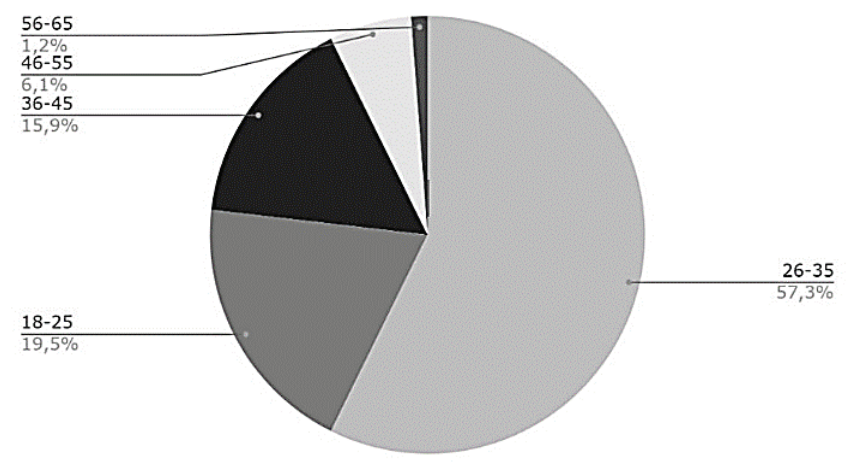

Figure 2 Age of respondents

The graph shows that the age structure of the respondents is different. The majority of respondents were aged 26 to 35 years or $57.3 \%$, followed by respondents between 18 and 25 years or $19.5 \%$. Respondents aged 36-45 accounted for $15.9 \%$, followed by respondents aged $46-55$ years or $6.1 \%$ and aged $56-65$ years or $1.2 \%$.

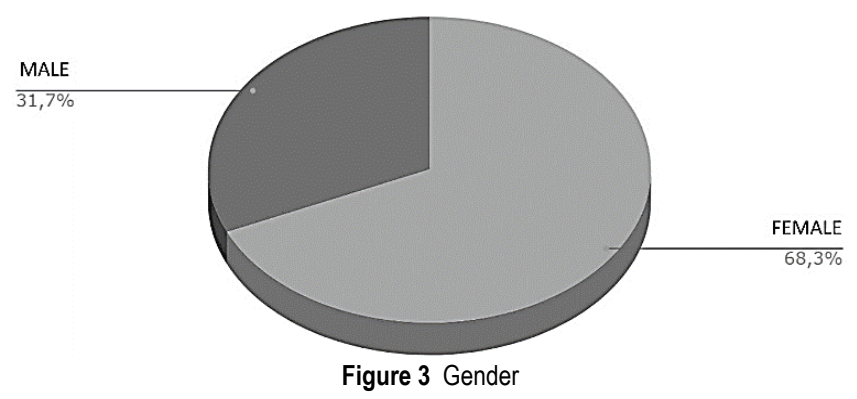

As mentioned earlier, 55 women or $68.3 \%$ of the total surveyed and 26 men or $31.7 \%$ of the respondents accessed the survey.
The third question asked was: "It is more important for me in teamwork to be right than to work well with others." The highest number of respondents or $39.02 \%$ said that it was rarely important for them to be right, and $35.36 \%$ said that it was not important for them to be right at all, but more important for them was to maintain good team relations.

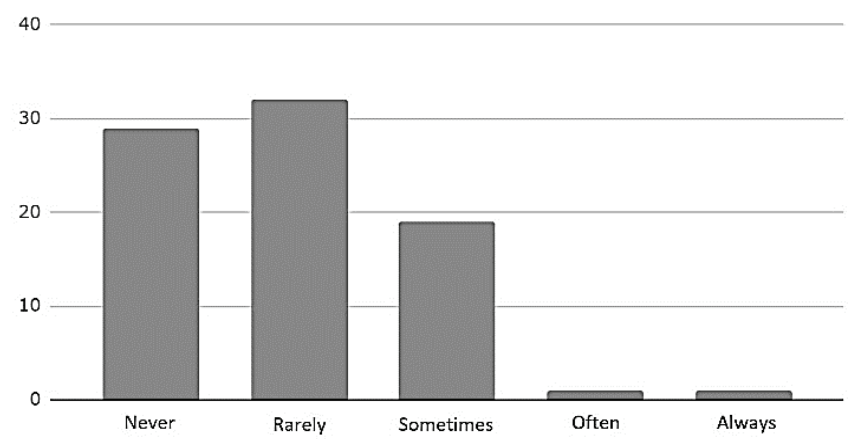

Figure 4 In teamwork, it is more important for me to be right than to work well with others

Furthermore, $23.18 \%$ of the respondents answered that it is sometimes more important for them to be right, and $1.22 \%$ of respondents must be often or always right.

Fig. 4 refers to the results of the respondents to question 4 , which says "I defend my position when someone disagrees with me." According to the data in the graph, $52.44 \%$ of the respondents answered the question affirmative, that is, they always defend their position, and $31.01 \%$ do it often.

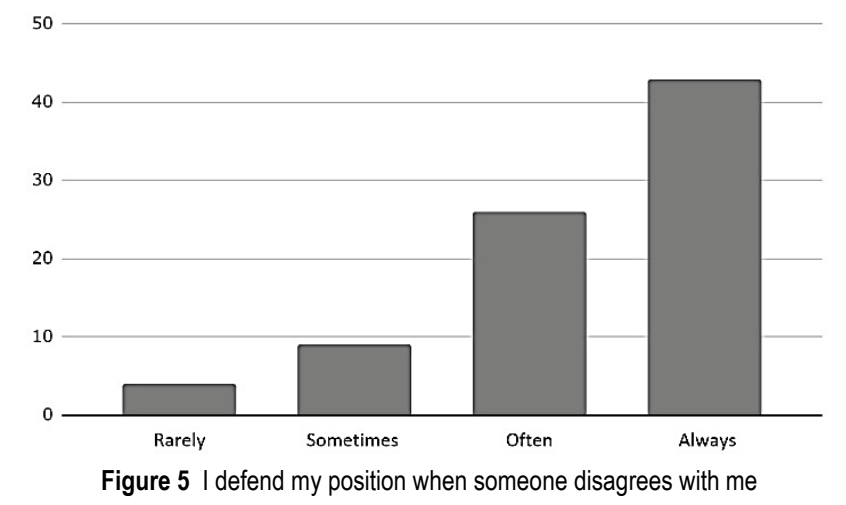

$10.97 \%$ of respondents answered that they defend their attitude sometimes and $4.87 \%$ defend their personal views rarely. None of the respondents answered that they never defend their views.

Fig. 5 refers to how often respondents listen to the advice of others, although they sometimes disagree with them. The graph shows that $41.46 \%$ of respondents always listen to the advice of others, and $30.49 \%$ of respondents often.

A total of $6.1 \%$ of respondents said they rarely or never listen to the advice of others.

The next question asked was "I do not like to be in conflict with others, so I often give in". $1.29 \%$ of the surveyed never yield, and $2.44 \%$ always yield. Fig. 6 shows the data listed. 
Furthermore, $37.80 \%$ or the majority of respondents answered that they sometimes give in, and $31.7 \%$ often do. $26.83 \%$ of respondents rarely give in.

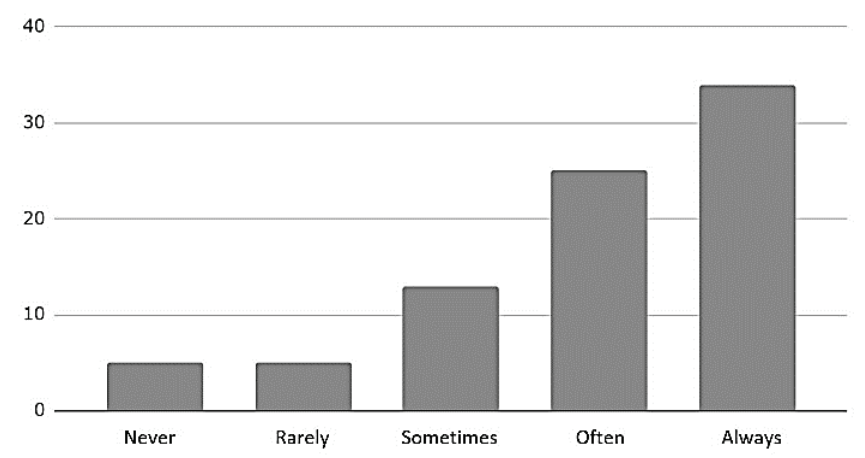

Figure 6 I listen to the advice of others even though I sometimes disagree with them

Fig. 7 gives information regarding whether respondents retain their opinions for themselves not to get in conflict with others. The majority of respondents answered that they rarely keep their opinions to themselves, $32.92 \%$ to be exact, and $30.49 \%$ always express them.

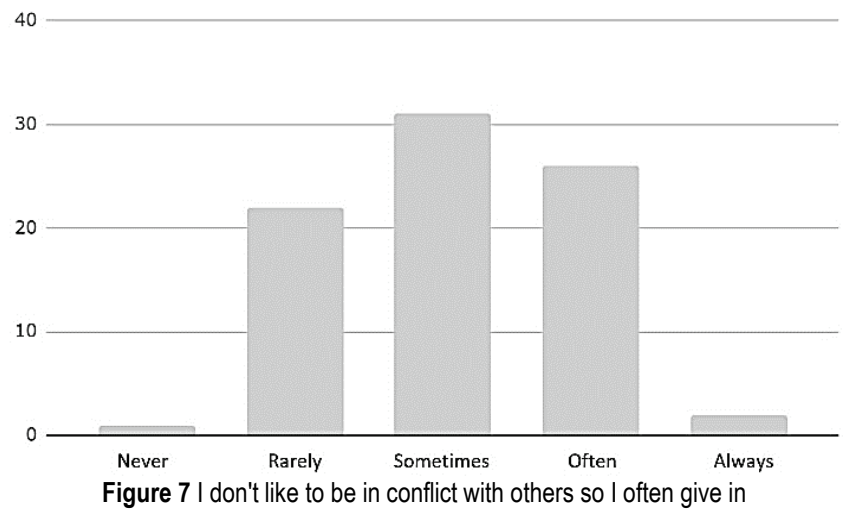

$12.19 \%$ of respondents sometimes keep their oppinions for themselves and $19.51 \%$ of the respondents often. $4.87 \%$ of respondents always keep their oppinions for themselves.

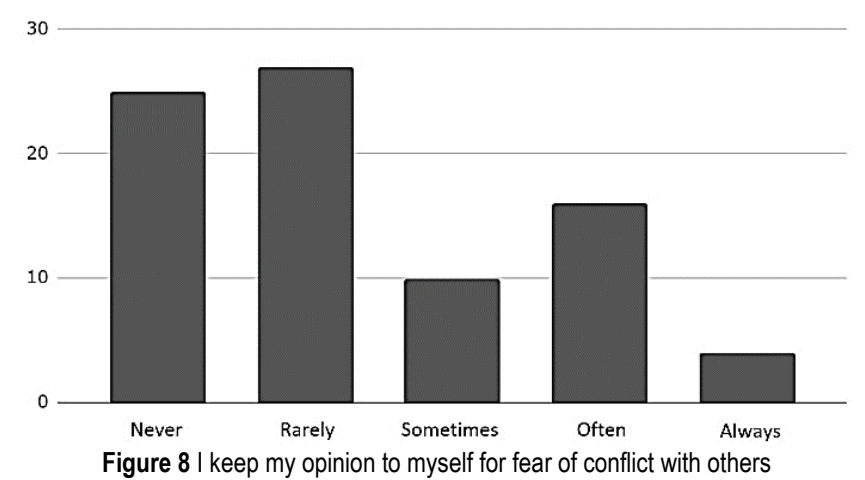

Fig. 8 concludes that the largest number of respondents or $48,7 \%$ try to get the best out of the conflict for both parties. It is often done by $41.46 \%$ respondents. Just $9.76 \%$ of respondents sometimes come out of conflict in a win-win situation.

None of the respondents answered that they rarely or never try to bring out the best for both parties. Fig. 9 shows how often people are willing to give in just not to jeopardize the relationship.

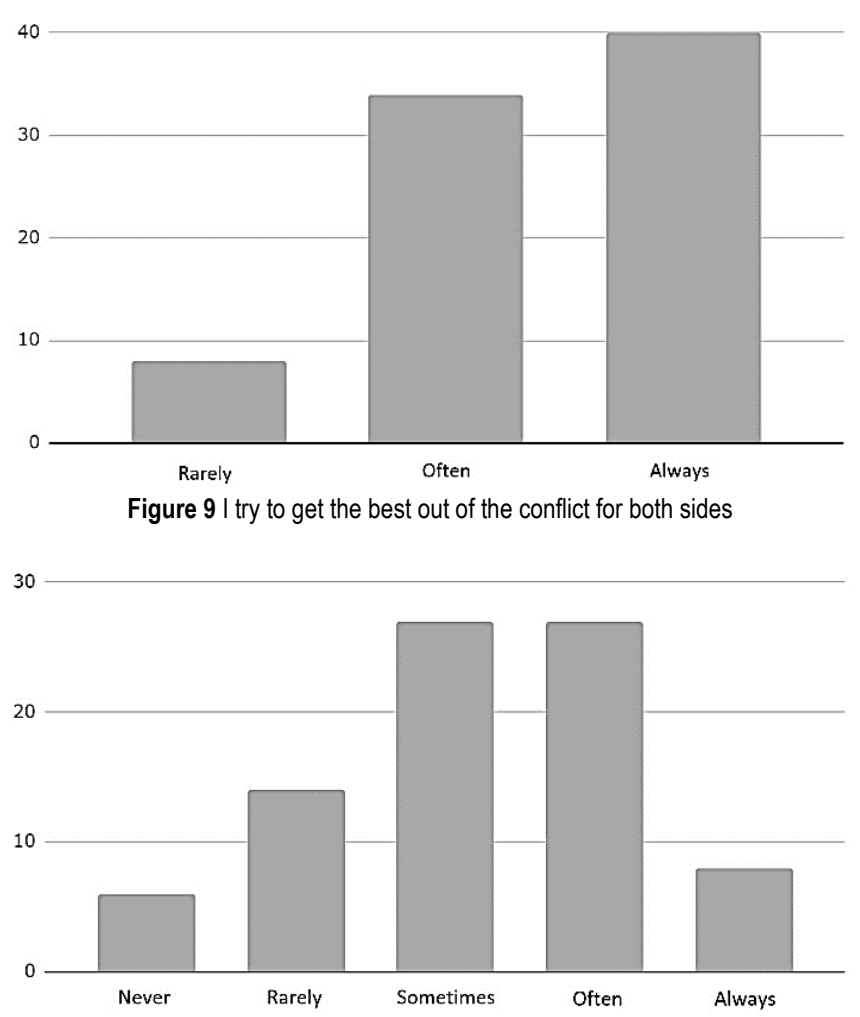

Figure $10 \mathrm{I}$ am ready to give in to others so as not to jeopardize our relationship

The majority of respondents or $32.93 \%$, sometimes or often give in to others. It will rarely be done by $17.07 \%$ of respondents, never by $7.31 \%$. A smaller number of respondents or $9.76 \%$ will always give in for good workplace relations.

When in conflict, respondents almost always talk to another person to find a common solution to the existing problem.

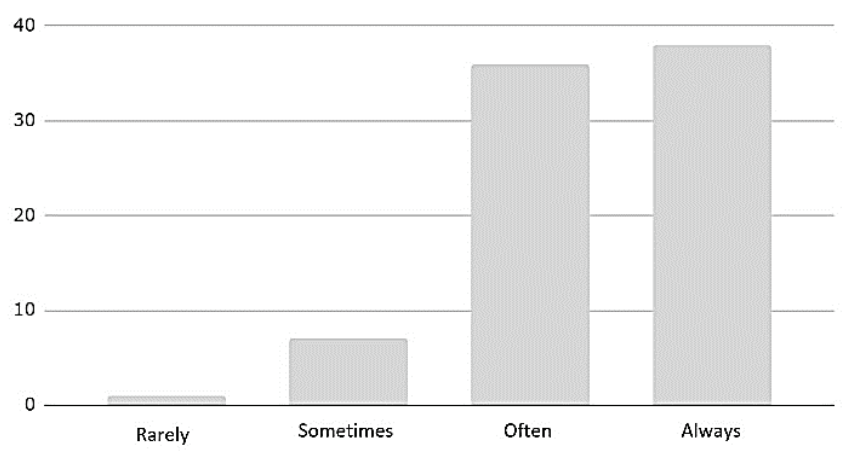

Figure 11 I speak openly with the person I am in conflict to find a solution

According to the survey results, $46.38 \%$ of respondents always talk openly with another person, and $43.90 \%$ often. 
Sometimes the problem is discussed by $8.54 \%$, rarely by $1.22 \%$ of the respondents. None of those interviewed answered that they never talk to another person they have a conflict with.

Fig. 11 shows how often the problem with another person is stated to the superior.

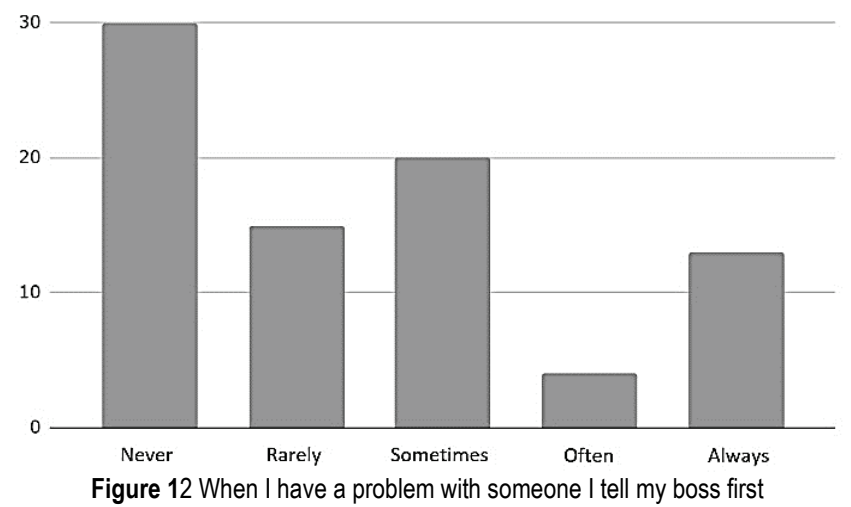

A large number of respondents or $36.58 \%$ never presents the problem to the boss, but tries to solve it independently. $18.29 \%$ of respondents will rarely, and $24.39 \%$ of respondents will sometimes address their superiors. $4.88 \%$ of the respondents often addres their boss and $15.85 \%$ always do.

The last question asked in the survey is whether people intentionally provoke others just to cause conflict.

According to the data seen in Fig. 12, it can be concluded that the majority of those surveyed, namely $87.8 \%$, never do so. It will rarely be done by $1.22 \%$ of respondents. Sometimes a conflict is provoked by $9.75 \%$ and often by $1.22 \%$ of respondents.

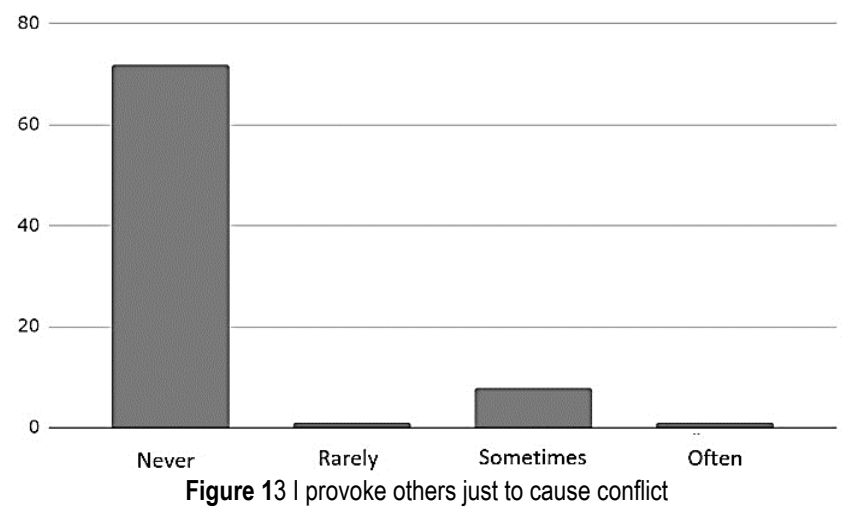

Based on all of the above, an equation can be defined through the basic components of organizational behavior:

$$
\mathrm{ORB} \text { ing }=\mathrm{ORB} \text { ind }+\mathrm{ORB} \text { inv }+\mathrm{ORB} \text { before }+\mathrm{ORB} \text { conf }
$$

ORB - Organizational Behavior

ORB ing - Organizational Behavior (as management engineering)

ORB ind - Organizational Behavior (identifying the behavior of members of the organization)
ORB inv - Organizational Behavior (exploring basic models of organizational behaviour)

ORB pre - Organizational Behavior (predicting the behavior of organization members)

ORB conf - Organizational Behavior (estimation of the level of conflict in the organization).

Estimating and listing these variables can lead to the value of an unknown variable, if necessary, and to the overall state of organizational behavior, based on which conclusions and decisions can be made.

\section{CONCLUSION AND RECOMMENDATIONS}

Leadership is the only true function of management because it cannot be transferred to others. It is considered to be one of the most important factors for the success of all companies, regardless of their primary activity. [6] For a long time, organizing and operating an enterprise was considered to be a rational process in which emotions have no place, while today it is believed that expressing positive emotions has a very positive effect, which comes to expression when connected emotionally and rationally. The importance of social dimension, ie to understand the human behavior and needs at the workplace for increasing organizational performance was emphasized by behavioral theories according to which participatory management presents the best way to use human resources. Effective leadership requires well-developed emotional intelligence, and every good leader uses his or her own emotional intelligence power rather than positional power.

A conflict is a situation in which two parties, individuals or groups, want to achieve a goal that they believe can be achieved by only one party. [7] Conflicts between different interests are inevitable in every business organization, so it should not be a surprise when the number and intensity of conflicts sometimes are very high. Conflict resolution is a skill without which managers could hardly succeed in their business. A manager must be competent to recognize a situation that can lead to conflict and to deal with that situation in a way that makes employees happy without harming the organization.

In order to answer the question of how people respond to conflict situations in the workplace and how they handle it, a survey was conducted on a sample of 82 people. The results of the survey are in line with the general perception but with some discrepancies, which is evident from the analysis of the results. The hypothesis $\mathrm{H} 1$ set in the paper is proven.

It is more important for the outcasts to work with the team than the fact that they are right. Most respondents will defend their position if someone disagrees with them, and most will obey the advice of others even though they disagree. The majority of respondents do not like to be in conflict with others, so for this reason they sometimes relent in conflict situations. Respondents rarely keep their position to themselves for fear of clashing with others, and winning the debate is rarely more important to them than the feelings of others. Most are trying to get the best out of conflict for both sides. For this reason, respondents often adapt to the 
demands of others, but they also firmly stand behind their opinions in negotiations. Respondents are sometimes, or often, willing to stumble, so as not to compromise their relationship with others, and always talk to the person they are in conflict with in order to find a common solution. For the most part, respondents do not inform the superior about the conflict first and never provoke others to cause conflict.

From the stated fact that employees do not inform the management about the existing conflict, a key question arises: How to manage conflict in production organizations if we do not know that it exists? It is a key hypothetical question for further research and is the subject of study of numerous systems and activities because it is crucial in building an organizational culture climate that is a prerequisite for success.

In this paper, leadership was seen as the ability to influence the group in terms of managing conflicts in order to achieve organizational goals. For a long time, workplace conflicts were considered a bad thing that should be avoided. However, a conflict-free group is immune to change and innovation. For this reason, a certain amount of conflict within a group is desirable in order to remain creative and self-critical. The role of the leader in conflict situations is crucial, as the leader needs to recognize conflict situations and deal with them through dialogue and compromise, always bearing in mind the primary goal - the well-being of the organization and the achievement of its goals. Certain levels of conflict within an organization can have positive consequences for individuals as well as groups and for the organization as a whole, giving people the opportunity to identify issues and opportunities that go unnoticed. It is one of the most challenging tasks for managers to know how to manage conflicts becouse the outcomes should be positive for both the organization and the employees. The survey concludes that people respond differently to conflicts. Most respondents try to solve the problem by talking, they often keep their opinions to themselves in order to avoid conflict at all, rarely involve their superior in the conflict, etc., which ultimately leads to the conclusion that most people respond positively to conflicts which are resolved by conversation and compromise. This is desirable at the personal level, but can be crucial at the organizational level.

\section{REFERENCES}

[1] Buble, M. (2011). Poslovno vođenje. Zagreb. M. E. P

[2] Srića, V. (2004). Biblija modernog vođe. Zagreb. Znanje

[3] Karlić, T. \& Hadelan, L. (2011.) Stil vođenja u funkciji uspješnog poslovanja tvrtke. Praktični menadžment, 2(3), 6772. Retrieved from https://hrcak.srce.hr/76455

[4] Polić, I. (2019), Leadership styles determine proactivity of employees - A vessel's example. Pomorski zbornik, 56(2019), 39-58.

[5] Samanta, I. \& Lamprakis, A. (2018) Modern leadership types and outcomes: the case of Greek public sector. Management, 23(1), 173-191. https://doi.org/10.30924/mjcmi/2018.23.1.173

[6] Miloloža, I. (2018) Analysis of the leadership style in relation to the characteristics of Croatian enterprises. Interdisciplinary Description of Complex Systems, 16(2), 249-264. https://doi.org/10.7906/indecs.16.2.5
[7] Garača, N. (2014) 1, 2, 3, 4... Menadžment. Virovitica. Visoka škola za menadžment u turizmu i informatici u Virovitici.

[8] Sherbakov, I. D. (2014). Conflict in organizations: their causes and resolution. Economics and management of innovation technologies, 30(3). http://ekonomika.snauka.ru/2014/03/4610

[9] Rijavec, M. \& Miljković, D. (2002.) Kako rješavati konflikte. Zagreb. IEP

[10] Certo, S. \& Certo T. (2009). Moderni menadžment. $10^{\text {th }}$ edition. Zagreb. MATE

[11] Dessler, G. (2015). Upravljanje ljudskim potencijalima. Zagreb. MATE

[12] Karbowski, A. \& Prokop, J. (2018) R\&D activities of enterprises, product market leadership, and collusion. Zbornik radova Ekonomskog fakulteta Rijeka, 36(2), 735-753.

[13] Putarek, V. \& Vlahović-Štetić, V. (2019) Metacognitive Feelings and Illusion of Linearity. Psychological Topics, 28(1), 171-192. https://doi.org/10.31820/pt.28.1.9

[14] Shafique, I., Kalyar, M. N., \& Ahmad, B. (2018) The nexus of ethical leadership, job performance, and turnover intention: the mediating role of job satisfaction. Interdisciplinary Description of Complex Systems, 16(1), 71-87. https://doi.org/10.7906/indecs.16.1.53

[15] Erceg, A. (2019). Information security: threat from employees, Tehnički glasnik, 13(2), 123-128. https://doi.org/10.31803/tg-20180717222848

\author{
Authors' contacts: \\ Jerko GLAVAŠ, PhD, Associate Professor \\ Faculty of Economics in Osijek, \\ Josip Juraj Strossmayer University in Osijek, \\ Trg Ljudevita Gaja 7, 31000 Osijek, Croatia \\ Tel: 00385312244 00, E-mail: jerko.glavas@efos.hr \\ Veljko KONDIĆ, mag. ing. mech. \\ University North, \\ Trg dr. Žarka Dolinara 1, 48000 Koprivnica, Croatia \\ E-mail: veljko.kondic@unin.hr \\ Iva BALIĆ, student \\ Faculty of Economics in Osijek, \\ Josip Juraj Strossmayer University in Osijek, \\ Trg Ljudevita Gaja 7, Osijek, Croatia \\ E-mail: ivbalic@efos.hr
}

